TI 2007-053/3

Tinbergen Institute Discussion Paper

\title{
Welfare State and Life Satisfaction: Evidence from Public Health Care
}

\author{
Jani-Petri Laamanen* \\ Kaisa Kotakorpi
}

University of Tampere, Finland, and FDPE.

* Invited visitor Tinbergen Institute. 


\section{Tinbergen Institute}

The Tinbergen Institute is the institute for economic research of the Erasmus Universiteit Rotterdam, Universiteit van Amsterdam, and Vrije Universiteit Amsterdam.

Tinbergen Institute Amsterdam

Roetersstraat 31

1018 WB Amsterdam

The Netherlands

Tel.: $\quad+31(0) 205513500$

Fax: $\quad+31(0) 205513555$

Tinbergen Institute Rotterdam

Burg. Oudlaan 50

3062 PA Rotterdam

The Netherlands

Tel.: $\quad+31(0) 104088900$

Fax: $\quad+31(0) 104089031$

Most TI discussion papers can be downloaded at http:/ /www.tinbergen.nl. 


\title{
Welfare State and Life Satisfaction: Evidence from Public Health Care*
}

\author{
Kaisa Kotakorpi ${ }^{\dagger}$ and Jani-Petri Laamanen ${ }^{\ddagger}$ \\ University of Tampere and FDPE
}

July 4, 2007

\begin{abstract}
We examine the effect of publicly provided health care on welfare by combining local level data on public health care, and individual level data on life satisfaction. It is shown that relatively high expenditures in health care have a positive effect on individuals' life satisfaction in our data. We further illustrate how life satisfaction data can be used to directly test theoretical hypotheses about how the welfare effect of public provision should vary among different groups in the population. We find some evidence for an "ends-against-the-middle" equilibrium (Epple and Romano, 1996) in the provision of public health care, where middle-income individuals prefer higher public expenditure at the margin than low-income or high-income individuals. Further, our results indicate that valuation for health care depends on individual political orientation.
\end{abstract}

Keywords: Life satisfaction, public provision, health care

JEL codes: H44, I18

\footnotetext{
${ }^{*}$ We would like to thank Markus Lahtinen, Hannu Laurila, Maarten Lindeboom, Heikki Loikkanen, Pentti Meklin, Jukka Pirttilä, Olli-Pekka Ruuskanen, Jari Vainiomäki, Frans van Winden and participants of the Spring Meeting of Young Economists 2007, PEARLE 2007 Seminar, and seminars at the Tinbergen Institute, Labour Institute for Economic Research and HECER for helpful comments and discussions. All remaining errors are ours. Kotakorpi gratefully acknowledges financial support from the FDPE, Yrjö Jahnsson Foundation and the Foundation for Economic Education. Laamanen gratefully acknowledges financial support from the FDPE and the Yrjö Jahnsson Foundation and thanks the Tinbergen Institute Amsterdam for hospitality during his stay in 2006-2007.

$\dagger$ Address: Department of Economics and Accounting, FI-33014 University of Tampere, Finland. Tel: +358-3-3551 6050. Fax: +358-3-3551 7214. E-mail: kaisa.kotakorpi@uta.fi

¥Address: Department of Economics and Accounting, FI-33014 University of Tampere, Finland. Tel: +358-3-3551 7567. Fax: +358-3-3551 7214. E-mail: jani-petri.laamanen@uta.fi
} 


\section{Introduction}

The value of many of the services typically associated with the welfare state is difficult to measure, as many of these services have public goods characteristics. Further, even if some publicly provided services are essentially private in nature (such as in the case of health care and education), individuals' valuation for them cannot in most cases be observed directly as they are often offered free of charge or at heavily subsidised prices by the government.

Frey and Stutzer (2005) provide an extensive discussion of the problems associated with attempting to value public goods by traditional revealed preference and stated preference methods, and they argue for the use of individual level life satisfaction data for this purpose. This method also has potential as a way of evaluating the welfare effects of the public provision of private goods. Adopting the life satisfaction approach is also parallel with the more general view, expressed for example by Layard (2005), according to which life satisfaction, or happiness, should be considered as the objective for public policies. The objective of the current paper is to examine the welfare effect of publicly provided health care by combining individual level data on self-reports of life satisfaction by Finnish respondents of the World Values Survey for the year 2000, with local level data on public health care services.

Paradoxically, in a cross-country study of 40 nations in 1980-90, Veenhoven (2000) finds no link between the size of the welfare state and the level of well-being ${ }^{1}$ of a country's citizens. Further, in another cross-country study of 74 countries, Bjornskov et al. (2007) find a negative effect of higher government spending on life satisfaction, interpreted as reflecting the tendency of rent-seeking politicians to overspend in order to maximise re-election probabilities. However, in these studies the amount of spending is not carefully scaled by any measure of service output. It is likely that individual welfare is affected primarily by the level of service provision, and not by aggregate expenditures per se. Indeed, Di Tella et al. (2003) use individual level data from 13 countries, and find a positive welfare effect of a more specific measure of the welfare state, namely the income replacement rate of unemployment benefits.

We aim to examine the effect of public services on well-being in more detail by using local level data and concentrating on a single sector. The World Values Survey includes a question on the respondents' place of residence, and we are therefore able to match the data with measures of the level of public health care services at the municipal level. The municipality level is the level at which primary health care is mainly organised

\footnotetext{
${ }^{1}$ The terms life satisfaction and well-being are used interchangeably in this paper.
} 
in Finland, and it is also the lowest level of local government. In the analysis, we construct a proxy for the level of service provision by using health care expenditure data, together with measures for service output. Our results indicate that, controlling for individual characteristics and local conditions, increasing expenditures (relative to output) in public health care has a positive effect on citizens' life satisfaction in our data.

A further contribution of our paper is that we illustrate how subjective well-being data can be used to provide direct tests of theoretical hypotheses about how the welfare effects of public provision should vary among different groups in the population. Firstly, we find some evidence for an "ends-against-the-middle" equilibrium (Epple and Romano, 1996) in the provision of public health care, where middle-income individuals prefer higher public expenditure at the margin than low-income or high-income individuals. The intuition is that health care is a normal good, and hence demand (for public and private health care taken together) is increasing in income. However, also the tax price of public health care increases in income. Hence the preferred level of public provision can be a non-monotonic function of income.

Secondly, we examine whether the willingness to pay for public health care differs according to whether the individual classifies himself as being right-wing or left-wing on the political spectrum. We find that those who classify themselves as right-wing have lower willingness to pay for primary health care, but perhaps surprisingly, higher willingness to pay for special health care. Finally, we examine a closely related question, namely whether the willingness to pay is inversely related to an individual's belief in a just world, as suggested by Benabou and Tirole (2006). However, we find no evidence for this.

Our paper is closely related to a number of studies that examine the welfare effect of public goods (or public bads) using happiness or life satisfaction data. Frey et al. (2004) and Frey and Stutzer (2005) assess the value of security by using regional level data from the UK and France on terrorist attacks, together with individual level data on life satisfaction ${ }^{2}$. Alesina et al. (2004) find a negative effect of economic inequality on happiness, combining individual level data on happiness and income inequality measured at the country level. Their study is closely related to ours, as redistribution is one of the central activities of modern governments. Another related paper is van Praag and Baarsma (2005), who use individual level life satisfaction data to evaluate the welfare effects of a negative externality, namely airport noise from Amsterdam airport. Welsch (2002) has conducted a cross-country study of the effect of urban air

\footnotetext{
${ }^{2}$ See also Powdthavee (2005) on how living in a high-crime area affects well-being.
} 
pollution on average life satisfaction. To our knowledge, no previous study has used local level data on public services, together with life satisfaction data, to evaluate the welfare effects of public service provision.

The rest of the paper proceeds as follows. In section 2, we discuss the data and the empirical methodology used. The basic results of the paper are presented in Section 3. Section 4 discusses how the results vary among different groups in the population. In Section 5, the results and their robustness are discussed in more detail. Finally, section 6 concludes.

\section{Data and methodology}

\subsection{Empirical model of well-being}

We use Finnish life-satisfaction data from the World Values Survey conducted in the year 2000. ${ }^{3}$ The data has approximately 1000 respondents. ${ }^{4}$ We run the following ordered probit regression:

$$
s_{i m r}=x_{i m r}^{\prime} \beta+z_{m r}^{\prime} \gamma+\delta_{r}+\varepsilon_{i m r},
$$

where $s_{i m r}$ is the self-reported life satisfaction of individual $i$ in municipality $m$ in province $r$. We interpret self-reported life satisfaction as being an indication of the latent continuous variable, individual well-being, that we cannot observe directly. $x_{i m r}$ is a vector of individual level explanatory variables and $z_{m r}$ is a vector of municipality level variables, including the measures of the level of health care services that are our main focus. Further, $\delta_{r}$ is a province dummy, and $\varepsilon_{i m r}$ is an error term. Because some of the regressors are measured at the municipal level while observations are at the individual level, we need to account for the possibility that the error terms of individuals in the same municipality may be correlated (see Moulton (1986)). We therefore use robust standard errors that allow for such correlation.

As our dependent variable, we will use individuals' answers to the World Values

\footnotetext{
${ }^{3}$ Even though the WVS was also conducted in 1995 and 2005, we are unfortunately only able to utilise data for the year 2000. Data from other years is hard to combine with our data, as some key variables (such as personal income) are measured differently in the different waves of the survey. The year 2000 is the only year with a measure of net income. Further, accounting practices of Finnish municipalities underwent a major change in 1996 and therefore the cost variables that are central to our analysis would not be comparable betweem the year 1995 and the latter years.

${ }^{4}$ In the analysis, we include respondents in economically active age (15-74). The elderly are likely to be treated within elderly care, which is organised separately from public health care.
} 
Survey question "'Overall, how satisfied are you with your life these days?", where individuals evaluate their satisfaction with life on a ten point scale. The World Values Survey data also includes a question where individuals are asked to evaluate how happy they are. However, happiness is much more imprecisely measured in the data than life satisfaction, as it is only evaluated on a four point scale. Concentrating on life satisfaction data is in line with the earlier related literature on European countries (see for example Alesina et al. (2004), Di Tella et al. (2001) and (2003)).

The use of subjective well-being data in formal econometric analysis often raises concerns among economists. We use ordered probit in our estimations, which requires that the life satisfaction measure needs to be ordinally comparable between people: that is, we require that a person who reports a life satisfaction score of 10 is in some objective sense better off than a person who reports a score of $9 .{ }^{5}$ One major concern is, whether this assumption is valid. The use of subjective well-being data is discussed and defended, among others, in Alesina et al. (2004) and Di Tella et al. (2003). Di Tella et al. (2003) point out that even if cross-person comparisons of the life satisfaction measure are not perfectly reliable, this is less of a problem in large samples and given that these variables are used only as dependent variables, as we do in the present study.

Ferrer-i-Carbonell and Frijters (2004), on the other hand, emphasise the importance of controlling for individual-level unobserved factors by using panel data methods. However, individual-level panel data is rarely available. ${ }^{6}$ Compared to most of the earlier studies that we have cited, where no panel data has been available, we are able to make some progress in controlling for unobserved individual level factors by including additional individual level variables (notably controlling for whether the individual has an active social life).

\subsection{Measuring the level of public health care services}

The respondents in our data come from approximately 140 different municipalities. The municipality level is the level at which public primary health care is mainly organised in Finland ${ }^{7}$, and it is also the lowest level of local government: in the year 2000, there

\footnotetext{
${ }^{5}$ However, we do not assume cardinality of the life satisfaction measure, which would be required if OLS were used in estimation.

${ }^{6}$ For related studies where individual-level panel data has been used, see Winkelmann and Winkelmann (1998) on life satisfaction (using the German Socio-Economic Panel), Hamermesh (2001) on job satisfaction (using the GSOEP and the US National Longitudinal Survey of Youth) and Clark et al (2005) on satisfaction with one's financial situation (using the European Community Household Panel).

${ }^{7}$ Some small municipalities provide primary health care jointly with other municipalities. In special health care, services are provided by hospital districts, which are formed on average of 20 municipal-
} 
were 452 municipalities, and the average number of inhabitants in a municipality was approximately 12000 (with a median of 5 000). There is universal access to public health care and it is provided either free of charge or at a nominal user fee by the municipalities. For some health services (notably in primary health care and certain types of surgeries in special health care) there is also a private alternative available. Approximately $2 / 3$ of all health care services in Finland are provided by the public sector.

In order to examine the effect of publicly provided health care on welfare, we have obtained data on local governments' net expenditures on health services in each respondent's municipality. Total service charges paid by users, as well as revenue from selling services to other municipalities and to firms, have been netted out in order to obtain a measure of expenditures used for the benefit of inhabitants. Further, to construct a measure that is more closely related to the level of service provision, we have also collected data on the number of visits to public health centres and hospitals, and the total number of treatment days in public health care in primary and special health care in a given year.

Using a standard method, we estimate two simple health care cost functions ${ }^{8}$ : we first run a population-weighted ${ }^{9}$ regression of the log of net expenditures in primary health care on the log of treatment days in primary care and the log of visits to health centres. Secondly, we run a similar regression for special health care. We take the residuals from these regressions and use these as a measure of health care quality or level of service provision. The residuals measure the relative deviation of expenditures from costs that would be predicted by the quantity of output provided, and are therefore a measure of "excess" expenditure in health care. A priori it is of course not clear whether the residual in the estimated cost functions reflects health care quality or whether it is pure waste. It is important to recognise, however, that we do not need to make any assumptions about this. Rather, our results will indicate whether these excess costs are beneficial for welfare - see Section 5 for more discussion on this issue.

Significant cost differences between public service providers are a prevalent feature in many countries. Our results provide direct information on the welfare effects of ities.

${ }^{8}$ Our procedure for estimating the health care cost function corresponds to the deterministic cost frontier method, which has been commonly used for evaluating performance in industries such as health care - see for example Giuffrida and Gravelle (2001) for a discussion on this and other related methods. We have also experimented with other specifications for the cost function - see Section 5 for more discussion.

${ }^{9}$ We use population-weighting in order to account for the greater random variation of costs in small municipalities. 
these differences in the Finnish context but we believe that the results are likely to be relevant also for other countries, particularly for those with a similar health care system.

\subsection{Control variables}

We include similar individual level controls that have been used in previous studies on life satisfaction or happiness. Firstly, we control for the effect of net income. In the World Values Survey, individuals are asked to place themselves into one of ten income groups according to household net income. We turn this into a continuous income measure by using the midpoint of each income interval ${ }^{10}$. From our point of view it is important that the question asks about net income, and the income measure therefore takes into account taxes that are paid in order to finance public services (including health care).

Further, we control for age, gender, employment status, education, marital status, the number of children and religious belief. Due to the richness of the data, we are able to include additional individual level controls that describe whether the individual has a permanent personal relationship (for those who are not married or cohabiting with a partner), has an active social life, and whether the person has retired because of incapacity. A respondent is coded as having an active social life if she reports spending time with friends, colleagues, people from the same church or people from other organisations weekly or near weekly. Being retired and under the age of 58 is regarded as being retired because of incapacity, since retiring before this age is only possible for those with physical or mental ill-health ${ }^{11}$.

As for regional level controls, we will include province dummies ${ }^{12}$ and control for municipality level variables which may be correlated with the level of public services and life satisfaction. Average unemployment and average income are included, as they have been found to be significant explanatory variables in previous life satisfaction studies

\footnotetext{
${ }^{10}$ In order not to lose the observations in the highest income group, which is open ended, we use the lower bound for this group together with a dummy that eliminates the effects of the measurement error created. All our results are thus unaffected by using the lower bound (rather than some higher number) as the income level for this group.

${ }^{11}$ This is an attempt to partially control for personal health status. Unfortunately, we do not have direct information on the respondents' health status.

${ }^{12}$ Finnish municipalities are divided into 20 different provinces (out of which our sample includes 19). Our specification therefore assumes that the municipalities within each province do not differ in any relevant respects other than the municipal level factors that we include as controls. This is in our view a reasonable assumption, given the rich array of controls used and the small size of Finnish provinces.
} 
(see for example Di Tella et al. (2003), Clark and Oswald (1994)), and the macroeconomic situation may also affect a local government's budgeting decisions. Further, better public services may lead to higher house prices, which would partially offset the effect of public services on life satisfaction (see for example van Praag and Baarsma (2005)). In order to capture the full effect of public health care, we therefore control for the level of house prices in each municipality. Further, in order to control for possible covariation of health care expenditures with expenditures in other public services that may also affect welfare, we control for per capita expenditures of the municipality in other sectors (such as social services, education and culture, and administration). The municipal level variables have been obtained from separate registers of Statistics Finland and they therefore include information on all residents of the municipality (and are not calculated from the WVS sample).

\section{Results}

Our results from estimating equation (1) are presented in Table 1. Let us first turn to the results regarding the health care variables. Excess expenditures in primary health care have a significant and positive effect on life satisfaction. This result is qualitatively extremely robust, and holds for different ways of measuring excess costs (see Section 5 for more discussion). It is interesting that we find a positive effect for the entire population, even though some individuals use private health services: as was mentioned above, approximately $1 / 3$ of health care services in Finland are provided by the private sector. However, there are clear reasons why better public health care may have a positive impact on welfare, beyond those individuals who currently use public health care services: Firstly, better public services are a form of social insurance ${ }^{13}$. Secondly, there may be positive externalities from a well-functioning public health care system. ${ }^{14}$

However, expenditures in special health care seem not to have a significant impact on well-being for the population taken as a whole. There are a number of potential explanations for this result. Firstly, the valuation of special health care varies widely across different groups in the population: in the following section, we show that the welfare effect of special health care is significant and positive for middle-income individuals, but insignificant for low-income individuals. Secondly, and related to the

\footnotetext{
${ }^{13}$ For a recent contribution on the role of the public sector in providing insurance, see Pirttilä and Tuomala (2007).

${ }^{14}$ For a broader discussion of these and other rationales for public sector involvement in the market, see for example Atkinson and Stiglitz (1980, 5-8).
} 
Table 1. The Determinants of life satisfaction ${ }^{[1]}$.

\begin{tabular}{|c|c|c|}
\hline \multicolumn{3}{|l|}{ Dep. var: life satisfaction } \\
\hline \multicolumn{3}{|l|}{ Personal characteristics } \\
\hline Income & $0.0097^{* *}$ & $(0.0040)$ \\
\hline Age & $-0.0422^{*}$ & $(0.0250)$ \\
\hline Age squared & 0.0004 & $(0.0003)$ \\
\hline Male & -0.0016 & $(0.0698)$ \\
\hline \multicolumn{3}{|l|}{ Labour market status } \\
\hline Self-employed & -0.2094 & $(0.1349)$ \\
\hline Retired & 0.2701 & $(0.2383)$ \\
\hline Housewife & 0.1779 & $(0.1826)$ \\
\hline Student & -0.0454 & $(0.1771)$ \\
\hline Unemployed & $-0.2858^{* *}$ & $(0.1448)$ \\
\hline \multicolumn{3}{|l|}{ Education } \\
\hline Basic & $-0.5108^{* * *}$ & $(0.1542)$ \\
\hline High school & $-0.4301^{* * *}$ & $(0.1528)$ \\
\hline Vocational college & $-0.3610 * *$ & $(0.1506)$ \\
\hline Lower university degree & $-0.4855^{* * *}$ & $(0.1760)$ \\
\hline \multicolumn{3}{|l|}{ Marital status } \\
\hline Living together & $-0.2562^{* *}$ & $(0.1094)$ \\
\hline Widowed & $-0.4617^{* *}$ & $(0.2011)$ \\
\hline Divorced & $-0.4795^{* *}$ & $(0.1927)$ \\
\hline Separated & -0.0144 & $(0.3183)$ \\
\hline Never married & $-0.5745^{* * *}$ & $(0.1411)$ \\
\hline Personal relationship & 0.3210 & $(0.2022)$ \\
\hline Number of children & $0.1554^{* * *}$ & $(0.0540)$ \\
\hline Number of children squared & $-0.0207^{* * *}$ & $(0.0060)$ \\
\hline Religious & $0.1724^{* *}$ & $(0.0849)$ \\
\hline Social life & $0.3067^{* * *}$ & $(0.0790)$ \\
\hline Incapacity retirement & $-0.5965^{* *}$ & $(0.2848)$ \\
\hline \multicolumn{3}{|l|}{ Health care variables ${ }^{[2]}$} \\
\hline Excess expenditures in primary health care & $0.4147^{* *}$ & $(0.1688)$ \\
\hline Excess expenditures in special health care & 0.1157 & $(0.2878)$ \\
\hline \multicolumn{3}{|l|}{ Municipality level control variables } \\
\hline Log of average income & -0.1211 & $(0.5417)$ \\
\hline Unemployment rate & -0.9818 & $(1.7440)$ \\
\hline Log of house prices & -0.2442 & $(0.1916)$ \\
\hline Log of net expenditures in soc. services \& admin. & 0.2043 & $(0.2777)$ \\
\hline Log of net expenditures in education \& culture & 0.2539 & $(0.2111)$ \\
\hline Net expenditures in other sectors & -0.1916 & $(0.3430)$ \\
\hline
\end{tabular}

${ }^{[1]}$ Ordered probit regression including province dummies, $\mathrm{N}=847$. Robust standard errors have been used. $(*)$ denotes significance at $10 \%$ level, $\left({ }^{* *}\right)$ at $5 \%$ level and $\left({ }^{* *}\right)$ at $1 \%$ level. The omitted category is employed, married females with a higher university degree. ${ }^{[2]}$ See section 2.2 for the definition of excess expenditures. 
first point, the quality of primary health care is likely to be a more salient issue for the population taken as a whole, as primary health care is used much more frequently by the average citizen ${ }^{15}$. Thirdly, due to the organisation of the Finnish health care sector (see footnote 7 above), the municipalities are likely to have better control over primary health care than they do over special health care. Therefore, the ability of municipalities to transform additional expenditures into quality might be more limited in special health care. Finally, visits to hospitals are likely to be more heterogenous than visits to health centres in primary health care. Therefore, it may be the case that if a municipality has incurred high costs in special health care, the cases that have been treated may have been more severe or complex than elsewhere.

The coefficients of municipal level control variables turn out to be insignificant. Most of the signs, however, are in line with theoretical predictions. For example, local house prices have a negative effect on well-being. Also, the coefficient of average income is negative, possibly because the variable captures the effect of income of the comparison group of citizens (see also Ferrer-i-Carbonell (2005)). The coefficients on per capita expenditures in social services and administration, as well as in education and culture, are positive. On the other hand, the coefficient on per capita expenditures in other sectors is negative ${ }^{16}$. These additional expenditure variables simply serve as controls, and have not been scaled to take into account the amount of output produced. Therefore the result that they are not found to have an effect on welfare is in line with findings from previous literature, as explained in the introduction.

Turning next to the effect of individual level factors on life satisfaction, our results seem to make sense and they are broadly in line with earlier literature. This gives us confidence that the utility functions that we have estimated are well defined. Personal income has a significant and positive effect. We also tried including the square of income, or using the log of income, but the squared term was not significant and the linear specification gave the best fit. The results are unaffected by the choice of functional form.

Of other personal characteristics, age appears to have a U-shaped effect on life satisfaction $^{17}$, a result familiar from many earlier studies. Unemployed individuals

\footnotetext{
${ }^{15}$ The average per capita number of visits to health centres (primary health care) in our sample is 6, whereas the average citizen visited a hospital (special health care) only once in the year 2000 . Also the average number of days spent in treatment in primary health care is 1,5 times as high as the number of days spent in hospitals.

${ }^{16}$ This variable contains net costs from other sectors besides those that have been included separately. Some of the services in these sectors are sold instead of offered free of charge (e.g. water supply or waste management) and this variable can therefore be negative (and has thus not been included in logarithmic form like the other expenditure variables).

${ }^{17}$ The significance of the linear term is improved by including the squared term and the terms are
} 
are significantly less satisfied with their life than those who are employed. Further, being married or having a high education has a positive effect on well-being. In many studies, women have been found to be more satisfied with their lives than men, but in the Finnish data gender seems to have no effect at all. Having children has a highly significant but non-linear effect on life satisfaction in our data. Religious individuals, as well as those with an active social life, are also more satisfied with their life. Finally, retirement because of incapacity has a significant and negative effect on life satisfaction.

\section{Extensions}

\subsection{Differences between income groups}

In the current and the following subsection we will analyse how the welfare effect of public health care varies among different groups in the population. First, we focus on the theoretical result of Epple and Romano (1996), that the welfare effect of publicly provided private goods such as health care is in equilibrium likely to be highest for individuals with income just below the mean.

More specifically, Epple and Romano (1996) analyse a good that is provided by the public sector, but public provision can be supplemented by private purchases. They show that in this dual provision game, there are two types of equilibria. This occurs because there are two opposite forces present: the tax-price of public health care increases with income, and therefore individuals with highest income always prefer a zero level of public provision, as the private alternative is cheaper for them.

However, the increasing tax-price is countered by the fact that health care is a normal good, so that marginal willingness to pay (for public and private health care taken together) increases with income. The type of equilibrium that emerges depends on the relative magnitudes of the price and income elasticities (see also Kenny (1978)). If the income elasticity of demand is lower than the absolute value of the price elasticity, we get the first type of equilibrium where the most preferred level of public provision is (weakly) decreasing in income. In this case the voter with the median level of income is pivotal. However, if the income elasticity is higher than the price elasticity, we get another equilibrium where the most preferred choice increases with income for those with income below the mean (whereas individuals with income above the mean still prefer a zero level of public provision due to the presence of a private alternative). In this equilibrium, therefore, the choice of government expenditure corresponds to jointly significant (p-value 0.08). 
the preferences of a lower-than-median-income household and there is a coalition of middle-income households that prefer higher public expenditure at the margin, whereas a coalition of high and low-income households prefer a reduction. Epple and Romano (1996) argue that preferences for health care are such that this type of an "ends-againstthe-middle" equilibrium is the more likely outcome.

There are a number of previous studies, mainly using stated preference methods, on how the willingness to pay for health care varies between income groups. The typical finding is that the willingness to pay for health care or a specific treatment is monotonically increasing in income - an alternative that is not possible in the Epple and Romano model, which concerns the willingness to pay for public provision in the presence of a private alternative. This apparent inconsistency can be explained by two factors. Firstly, many studies simply ask about respondents' willingness to pay for health care (as in Whynes et al. (2003)) and do not differentiate between public and private services. These studies therefore show that the demand for public and private health care services taken together is increasing in income, a finding that is consistent with the Epple and Romano model. Indeed, the normality of health care is one of the key assumptions behind the model. Secondly, studies that specifically ask subjects to state their willingness to pay for public health care have typically not allowed for a non-linear effect of income - see for example Mataria et al. (2004) and Pavlova et al. (2004). No empirical studies that we know of have directly examined the Epple and Romano model or used subjective well-being data to assess individuals' valuation for health care.

To examine which of the two types of equilibria implied by the Epple and Romano model is consistent with our data, we construct dummies for low-income, middle-income and high income-individuals. In order to ensure consistency with the definitions of Epple and Romano, we define as middle-income individuals those individuals with income (approximately) in the second quartile ${ }^{18}$. We then run a similar regression as in (1), adding terms where we interact our measures of excess expenditures in public health care with the low-income and high-income dummies. The results are presented in Table 2. We only report the coefficients on health care expenditures and the interaction terms, as the results for all the other variables are virtually identical to the basic results presented in Table $1^{19}$.

\footnotetext{
${ }^{18}$ Individuals in our data are divided into ten groups according to income. We define groups $1-3$ as low income, 4-6 as middle-income and 7-10 as high income. Our qualitative results are robust to other sensible divisions as well.

${ }^{19}$ We have not included dummies for the low-income and high-income groups, as they contain no new information in addition to the income variable, which is included and remains significant.
} 
Table 2. Differences in the welfare effect of public health care: income ${ }^{[1]}$.

\begin{tabular}{lll}
\hline \hline Dep. var: life satisfaction & & \\
Excess expenditures in primary health care & $0.7268^{* * *}$ & $(0.2556)$ \\
Excess expenditures in special health care & $0.7656^{*}$ & $(0.4106)$ \\
Low income*Excess expenditures in primary health care & -0.4477 & $(0.3959)$ \\
High income*Excess expenditures in primary health care & $-1.1026^{*}$ & $(0.5680)$ \\
Low income*Excess expenditures in special health care & $-0.8253^{*}$ & $(0.4518)$ \\
High income*Excess expenditures in special health care & -0.5089 & $(0.5273)$ \\
\hline
\end{tabular}

${ }^{[1]}$ Ordered probit regression including individual and municipal level controls and province dummies, $\mathrm{N}=847$. Robust standard errors have been used. (*) denotes significance at $10 \%$ level, (**) at $5 \%$ level and (***) at $1 \%$ level. The omitted category is middle-income individuals.

The significance of the coefficient on expenditures in primary health care is improved from the basic regression: this now measures the welfare effect of the public provision of primary health care for middle-income individuals. Further, it is interesting to note that also the welfare effect of special health care is significant (at the $10 \%$ level) for middle-income individuals, even though it was not significant for the whole sample. All of the interaction terms are negative and two of them are also statistically significant at the $10 \%$ level. There is therefore some evidence in our data that low-income and high-income individuals would prefer a lower level of public health care expenditures than middle-income individuals. In particular, high-income individuals appear to have a lower willingness to pay for primary health care, and low-income individuals for special health care, as compared with middle-income individuals. This heterogeneity can explain the fact that we did not get significant results on the welfare effect of special health care in the previous section, where the parameter on health care expenditures was constrained to be the same for all income groups.

Further, the overall welfare effect of public health care for low-income individuals is given by the sum of the expenditure coefficient and the coefficient of the relevant interaction term (similarly for high-income individuals). It is important to note that the overall effect for low-income individuals in special health care, as well as the overall effect for high-income individuals in primary health care, is negative. That is, the low-income individuals would prefer a reduction in expenditures in special health care (though the effect is not statistically significant) and similarly for high-income individuals in primary health care. Further, if we test the significance of the overall effect of public health care expenditures on the welfare of the low-income group and highincome groups in those sectors where the overall effect is positive ${ }^{20}$, these effects are

\footnotetext{
${ }^{20}$ That is, we test the linear restriction that the sum of the coefficient on primary care expenditures
} 
not significantly different from zero.

Our results therefore give support for the "ends-against-the-middle" equilibrium of the public provision game. Even though the evidence is not fully conclusive as some of the interaction terms are not significant, it should be noted that there is no evidence that supports the alternative equilibrium, where valuation for public health care should be monotonically decreasing in income.

\subsection{Differences based on political ideology}

It is also interesting to examine how the willingness to pay for public health care varies according to individual attitudes that are likely to be related to attitudes towards the public sector. We therefore analyse whether the willingness to pay for public health care varies according to whether the individual classifies himself as left-wing or rightwing on the political spectrum. Alesina et al. (2004) have conducted a similar analysis of the welfare effect of inequality, finding that in Europe, left-wingers are much more bothered about inequality than right-wingers.

In the World Values Survey, individuals are asked to state whether they consider themselves to be left-wing or right-wing on a ten point scale (where 1=left-wing and $10=$ right-wing). We split the spectrum in half and classify as "left-wing" those reporting numbers between 1 and 5, and the rest are classified as "right-wing".

We examine the question whether right-wingers have a lower willingness to pay for health care by again including the relevant interaction terms in our basic regression. The results are summarised in Table 3. The results indicate that the welfare effect of public provision of primary health care is positive and significant for leftwingers. Right-wingers on the other hand have a significantly lower willingness to pay for primary health care, as one might expect, and the overall effect for right-wingers is not significantly different from zero (the p-value is 0.47 ). Interestingly, however, right-wingers appear to have a higher willingness to pay for special health care. An explanation may be that public special health care is not as redistributive as public primary health care: for many types of severe illnesses that are treated in special health care, the private market is not well developed and the insurance aspect of public provision is likely to be important.

Finally, we have examined the related question of whether willingness to pay for public health care is higher for individuals who have a belief in a just world (BJW). Benabou and Tirole (2006) have suggested that such a belief is likely to be related to

and the coefficient on the interaction term for the low income group is zero, and similarly for the high income group in special health care. The p-value for the former test is 0.35 and for the latter 0.59 . 
Table 3. Differences in the welfare effect of public health: political ideology ${ }^{[1]}$.

\begin{tabular}{lll}
\hline \hline Dep. var: life satisfaction & & \\
Excess expenditures in primary health care & $0.8687^{* *}$ & $(0.3473)$ \\
Excess expenditures in special health care & -0.1873 & $(0.3594)$ \\
Right-wing & 0.1168 & $(0.0714)$ \\
Right-wing*Excess expenditures in primary health care & $-0.7345^{* *}$ & $(0.3613)$ \\
Right-wing*Excess expenditures in special health care & $1.0615^{* *}$ & $(0.4746)$ \\
\hline
\end{tabular}

${ }^{[1]}$ Ordered probit regression including individual and municipal level controls and province dummies, $\mathrm{N}=847$. Robust standard errors have been used. (**) denotes significance at $5 \%$ level. The omitted category is individuals who classify themselves as left-wing.

attitudes towards the public sector: roughly speaking, those who believe that the poor are poor because of bad luck are likely to support a larger public sector than those who believe that the poor are poor because they are lazy. A belief in a just world may also be related to political attitudes, so that those who believe in a just world are more likely to be right-wing (though in our data the correlation between the dummies for right-wing political attitudes and BJW is only 0.14).

The survey data that we use includes a question "Why are there people in our country who live in poverty? Please state the most important reason." The answer categories are 1) "they are unlucky"; 2) "they are poor because of laziness and lack of willpower"; 3) "they are poor because the society treats them unfairly"; 3) "it is an inevitable part of current developments" and 4) "none of the above". We have classified individuals who have given answer number two as those who believe in a just world, and the rest as not having such a belief. We have then included the relevant interaction terms in our basic regression. However, we find no evidence that individuals who believe that poor people are lazy prefer a lower level of public health care. A possible reason is that public health care is not used only by the poor, but also by higher income individuals: indeed, our results in section 4.1 indicate that middle-income individuals prefer a higher level of public health care services than low-income individuals.

\section{Discussion}

In the present section, we discuss a number of factors that might potentially cause problems for our analysis, and argue that our results are robust to these considerations.

Firstly, average treatment days and visits to health centres can be thought of as (very crude) proxies for individual health, as our data unfortunately does not contain 
direct information on the respondents' health status. Even though it is unlikely that individual level health status is correlated with municipality level health care variables, one might still worry that our results could be driven by the fact that better health leads to better quality of life. In other words, a high residual in the estimated health care cost function might not reflect unusually high quality, but might instead be a sign of unusually low levels of ill health, leading to unusually few visits to health centres for a given level of health care expenditures. In order to ensure that it is not only the negative effect of illness that is driving our results, we have run a similar ordered probit regression as in (1), but instead of using the residuals as our measure of health care quality, we have entered the net health care expenditures and the output measures as separate explanatory variables. The results of this regression are presented in Table 4.

The results in Table 4 confirm our earlier findings. In particular, net expenditures in primary health care have a positive and highly significant effect on life satisfaction. Of the other health care variables, only the number of days spent in treatment in primary health care turns out to have an effect on well-being. This can probably again be explained by saliency. We further experimented with using expenditure per treatment day or per visit as our measure of health care quality and our results remain unchanged.

Secondly, our results are broadly robust to other specifications of the health care cost function. As was explained in Section 2, the results that we have reported were obtained with the commonly used log-log specification for the health care cost function. We have experimented with a wide variety of other specifications: a linear cost function, a cost function that has been scaled by population of the municipality and a cost function where population has been included as a separate control variable. We have also tried leaving out the capital city of Helsinki from the analysis, as it can be expected to differ from other towns in a number of ways that may be relevant. Our results are broadly robust to all of these changes: in particular, the p-value of the primary health care cost coefficient is less than 0.06 in all the specifications that we have tried. Also most of the results regarding differences between population groups are qualitatively robust to these changes. One difference is that for some specifications, the willingness to pay for special health care appears to be monotonically increasing in income (though this pattern is never statistically significant). This can again be explained by the fact that the private market for services in special health care is not very well developed ${ }^{21}$.

\footnotetext{
${ }^{21}$ The reasons for this are likely to originate on the supply side of the market and are therefore exogeneous to the Epple and Romano model, which explains public provision of private goods by demand factors only.
} 
Table 4. The Determinants of life satisfaction ${ }^{[1]}$.

\begin{tabular}{|c|c|c|}
\hline \multicolumn{3}{|l|}{ "Dep. var: life satisfaction } \\
\hline \multicolumn{3}{|l|}{ Personal characteristics } \\
\hline Income & $0.0096^{* *}$ & $(0.0040)$ \\
\hline Age & $-0.0428^{*}$ & $(0.0251)$ \\
\hline Age squared & 0.0004 & $(0.0003)$ \\
\hline Male & 0.0001 & $(0.0701)$ \\
\hline \multicolumn{3}{|l|}{ Labour market status } \\
\hline Self-employed & -0.2129 & $(0.1342)$ \\
\hline Retired & 0.2604 & $(0.2394)$ \\
\hline Housewife & 0.1725 & $(0.1841)$ \\
\hline Student & -0.0466 & $(0.1771)$ \\
\hline Unemployed & $-0.2889^{* *}$ & $(0.1446)$ \\
\hline \multicolumn{3}{|l|}{ Education } \\
\hline Basic & $-0.5160 * * *$ & $(0.1566)$ \\
\hline High school & $-0.4325^{* * *}$ & $(0.1533)$ \\
\hline Vocational college & $-0.3615^{* *}$ & $(0.1511)$ \\
\hline Lower university degree & $-0.4911^{* * *}$ & $(0.1749)$ \\
\hline \multicolumn{3}{|l|}{ Marital status } \\
\hline Living together & $-0.2563^{* *}$ & $(0.1097)$ \\
\hline Widowed & $-0.4606^{* *}$ & $(0.1991)$ \\
\hline Divorced & $-0.4821^{* *}$ & $(0.1928)$ \\
\hline Separated & -0.0283 & $(0.3162)$ \\
\hline Never married & $-0.5775 * * *$ & $(0.1420)$ \\
\hline Personal relationship & 0.3209 & $(0.2040)$ \\
\hline Number of children & $0.1551^{* * *}$ & $(0.0542)$ \\
\hline Number of children squared & $-0.0203^{* * *}$ & $(0.0060)$ \\
\hline Religious & $0.1740^{* *}$ & $(0.0847)$ \\
\hline Social life & $0.3085^{* * *}$ & $(0.0792)$ \\
\hline Incapacity retirement & $-0.5921^{* *}$ & $(0.2867)$ \\
\hline \multicolumn{3}{|l|}{ Health care variables } \\
\hline Log of net expenditures in primary health care & $0.4281^{* *}$ & $(0.1965)$ \\
\hline Log of net expenditures in special health care & -0.0522 & $(0.3706)$ \\
\hline Log of visits to health centres (primary health care) & -0.1782 & $(0.2859)$ \\
\hline Log of visits to hospitals (special health care) & -0.1330 & $(0.2984)$ \\
\hline Log of days spent in treatment (primary health care) & $-0.1053^{* *}$ & $(0.0417)$ \\
\hline Log of days spent in treatment (special health care) & 0.0311 & $(0.2450)$ \\
\hline \multicolumn{3}{|l|}{ Municipality level control variables } \\
\hline Log of average income & -0.0014 & $(0.6503)$ \\
\hline Unemployment rate & -0.7153 & $(2.0824)$ \\
\hline Log of house prices & -0.2406 & $(0.2662)$ \\
\hline Log of net expenditures in soc. services \& admin. & 0.2119 & $(0.3127)$ \\
\hline Log of net expenditures in education \& culture & 0.2582 & $(0.2362)$ \\
\hline Net expenditures in other sectors & -0.1839 & $(0.3885)$ \\
\hline
\end{tabular}

${ }^{[1]}$ Ordered probit regression including province dummies, $\mathrm{N}=847$. (*) denotes significance at $10 \%$ level, $\left({ }^{*}\right)$ at $5 \%$ level and $(* * *)$ at $1 \%$ level. The omitted category is employed, married females with a higher university degree. 
Finally, it should be noted that treatment days and the number of visits to public health centres and hospitals are potentially endogenous to the health care expenditures of the municipality. To the extent that lower expenditures lead to lower quality, this might induce individuals to shift towards using private sector health services, which leads to an increase in expenditures per treatment day or visit. This causes a downward bias in our estimate for the effect of health care expenditures, and our estimates can therefore be regarded as the lower bound for these effects.

\section{Conclusions}

We have examined the impact of publicly provided health care services on individuals' subjective well-being. Our findings suggest that increasing expenditures in local service provision have a positive influence on the life satisfaction of inhabitants. Further, we have examined how this effect varies among different population groups. Our results provide support for the "ends-against-the-middle" hypothesis (Epple and Romano 1996), that the willingness to pay for publicly provided private goods such as health care may be non-monotonic in income. Further, welfare effects of health care spending depend on individual political orientation.

Taken together, our results show that monetary resources devoted to public service provision have a positive effect on well-being, although this effect may vary between population groups. This conclusion is in contrast with some earlier studies, which have not been able to find a positive effect. We have argued that when examining whether higher government expenditures increase well-being, it would be important to control for service output: it is likely that individual welfare is affected primarily by the level of services financed by government expenditures, and not by aggregate expenditures per se. In addition, it is important to note that if the welfare effects of public services vary between population groups, this may hinder finding positive and significant effects if we only examine the population taken as a whole.

Our results also have interesting implications for the popular debate on public provision of private goods, particularly the issue of whether high costs relative to the service output in the public sector are necessarily a sign of inefficiency. Our results indicate that (at least a part of) high costs in public health care are welfare improving, and therefore cannot be pure waste; rather, high costs are likely to be at least partly reflected in better quality of service. An interesting issue for further research is to try to disentangle these effects for example by finding suitable instruments for health care quality. The method used in our study could also be useful for determining the welfare 
effects of other publicly provided services.

\section{References}

Alesina, A., Di Tella, R. and MacCulloch, R. (2004). Inequality and happiness: Are Europeans and Americans different? Journal of Public Economics, 88, 2009-2042.

Atkinson, A. B. and Stiglitz, J. E. (1980). Lectures on public economics. Singapore: McGraw-Hill.

Benabou, R. and Tirole, J. (2006). Belief in a just world and redistributive politics. Quarterly Journal of Economics, 121, 699-746.

Bjornskov, C., Dreher, A. and Fischer, J. A. V. (2007). The bigger the better? Evidence of the effect of government size on life satisfaction around the world. Public Choice, $130,267-292$.

Clark, A., Etilé, F., Postel-Vinay, F., Senik, C. and Van der Straeten, K. (2005). Heterogeneity in reported well-being: Evidence from twelve European countries. Economic Journal, 115, C118-C132.

Clark, A. E and Oswald, A. J. (1994). Unhappiness and unemployment. Economic Journal, 104, 648-659.

Di Tella, R., MacCulloch, R. J. and Oswald, A. J. (2001). Preferences over inflation and unemployment: evidence from surveys of happiness. American Economic Review, 91, 335-341.

Di Tella, R., MacCulloch, R. J. and Oswald, A. J. (2003). The macroeconomics of happiness. Review of Economics and Statistics, 85, 809-827.

Easterlin, R. A. (2001). Income and happiness: Towards a Unified Theory. Economic Journal, 111, 465-484.

Epple, D. and Romano, R. E. (1996). Public Provision of Private Goods. Journal of Political Economy, 104, 57-84.

Ferrer-i-Carbonell, A. (2005). Income and well-being: an empirical analysis of the comparison income effect. Journal of Public Economics, 89, 997-1019. 
Ferrer-i-Carbonell, A. and Frijters, P. (2004). How important is methodology for the estimates of the determinants of happiness? Economic Journal, 114, 641-659.

Frey, B. S., Luechinger, S. and Stutzer, A. (2004). Valuing public goods: The life satisfaction approach. CESIfo Working Paper No. 1138.

Frey, B. S. and Stutzer, A. (2005). Happiness research: State and prospects. Review of Social Economy, 62, 207-228.

Giuffrida, A. and Gravelle, H. (2001). Measuring performance in primary care: econometric analysis and DEA. Applied Economics, 33, 163-175.

Hamermesh, D. S. (2001). The changing distribution of job satisfaction. Journal of Human Resources, 36, 1-30.

Kenny, L. W. (1978). The collective allocation of commodities in a democratic society: A generalization. Public Choice, 33, 117-201.

Layard, R. (2005). Happiness: Lessons From a New Science. New York and London: Penguin.

Mataria, A., Donaldson, C., Luchini, S., and Moatti, J.-P. (2004). A stated preference approach to assessing Health Care-Quality improvements in Palestine: From theoretical validity to policy implications. Journal of Health Economics, 23, 1285-1311.

Moulton, B. R. (1986). Random group effects and the precision of regression estimates. Journal of Econometrics, 32, 385-397.

Pavlova M., Groot W. and Van Merode G. G. (2004). Willingness and ability of Bulgarian consumers to pay for improved public health care services. Applied Economics, $36,1117-30$.

Pirttilä, J. and Tuomala, M. (2007). Labour income uncertainty, taxation and public good provision. Economic Journal, 117, 567-582.

Powdthavee, N. (2005). Unhappiness and crime: Evidence from South Africa. Economica, $72,531-547$.

van Praag, B. M. S. and Baarsma, B. E. (2005). Using happiness surveys to value intangibles: the case of airport noise. Economic Journal, 115, 224-246.

Veenhoven, R. (2000). Well-being in the welfare state: Level not higher, distribution not more equitable. Journal of Comparative Policy Analysis, 2, 91-125. 
Welsch, H. (2002). Preferences over prosperity and pollution: Environmental valuation based on happiness surveys. Kyklos, 55, 473-494.

Whynes D. K., Frew E. and Wolstenholme J. L. (2003). A comparison of two methods for eliciting contingent valuations of colorectal cancer screening. Journal of Health Economics, 22, 555-574.

Winkelmann, L. and Winkelmann, R. (1998). Why are the unemployed so unhappy? Evidence from panel data. Economica, 65, 1-15.

World Values Survey 2000: Finnish data. Version 4. Gallup Finland \& The Church Research Institute (conductor of survey). Finnish Social Science Data Archive (distributor), Tampere, 2003. 